\title{
Determinants of barley grain yield in drought-prone Mediterranean environments
}

\author{
Enrico Francia, ${ }^{1}$ Alessandro Tondelli, ${ }^{2}$ Fulvia Rizza, ${ }^{2}$ Franz W. Badeck, ${ }^{3}$ \\ William T.B. Thomas, ${ }^{4}$ Fred van Eeuwijk, ${ }^{5}$ Ignacio Romagosa, ${ }^{6}$ A. Michele Stanca, ${ }^{1,2}$ \\ Nicola Pecchioni ${ }^{1}$ \\ ${ }^{1}$ Department of Life Sciences, University of Modena and Reggio Emilia, Reggio Emilia, Italy; \\ ${ }^{2}$ CRA-GPG - Genomics Research Centre, Fiorenzuola d'Arda (PC), Italy; ${ }^{3}$ Potsdam Institute for \\ Climate Impact Research (PIK), Potsdam, Germany; ${ }^{4}$ The James Hutton Institute, Invergowrie, \\ Dundee, UK; ${ }^{5}$ Biometris - Applied Statistics, Wageningen University, Wageningen, The \\ Netherlands; ${ }^{6}$ Department of Crop and Forest Sciences, University of Lleida, Spain
}

\begin{abstract}
The determinants of barley grain yield in drought-prone Mediterranean environments have been studied in the Nure $\mathrm{x}$ Tremois (NT) population. A large set of yield and other morpho-physiological data were recorded in 118 doubled-haploid lines of the population, in multi-environment field trials (18 site-year combination). Agrometeorological variables have been recorded and calculated at each site too. Four main periods of barley development were considered, vegetative, reproductive early and late grain filling phases, to dissect the effect on yield traits of the growth phases. Relationships between agrometeorological variables, grain yield (GY) and its main components (GN and GW) were also investigated by correlation. Results firstly gave a clear indication of the involvement of water consumption in determining GY and GW $\left(r^{2}=0.616, \mathrm{P}=0.007\right.$ and $r^{2}=0.703$, $\mathrm{P}=0.005$, respectively) calculated from sowing to the early grain filling
\end{abstract}

Correspondence: Nicola Pecchioni, Dipartimento di Scienze della Vita, Università di Modena e Reggio Emilia, via Amendola, 2 - Pad. Besta, 42122 Reggio Emilia, Italy. Tel. +39.0522.522003 - Fax: +39.0522.522027.

E-mail: nicola.pecchioni@unimore.it

Key words: barley, developmental genes, Mediterranean environments, yield adaptation, water stress index.

Conference presentation: SIA Congress, Teramo 2011.

Acknowledgments: this work was funded by the European Union-INCO-MED program (ICA3-CT2002-10026) Mapping Adaptation of Barley to Drought Environments (MABDE).

Received for publication: 9 July 2012.

Revision received: 23 December 2012.

Accepted for publication: 23 December 2012.

(C) Copyright E. Francia et al., 2013

Licensee PAGEPress, Italy

Italian Journal of Agronomy 2013; 8:e1

doi:10.4081/ija.2013.e1

This article is distributed under the terms of the Creative Commons Attribution Noncommercial License (by-nc 3.0) which permits any noncommercial use, distribution, and reproduction in any medium, provided the original author(s) and source are credited. period, while GN showed its highest correlation with the total photothermal quotient $(\mathrm{PQ})$ calculated for the same period $\left(r^{2}=0.646\right.$, $P=0.013$ ). With the only exception of total $P Q$ calculated during the vegetative period, all significant correlations with $\mathrm{GY}$ were associated to water-dependent agrometeorological parameters. As a second result, the NT segregating population allowed us to weight the amount of interaction due to genotypes over environments or to environments in relation to genotypes by a GGE analysis; $47.67 \%$ of $\mathrm{G}+\mathrm{GE}$ sum of squares was explained by the first two principal components. Then, the introduction of genomic information at major barley genes regulating the length of growth cycle allowed us to explain patterns of adaptation of different groups of NT lines according to the variants (alleles) harbored at venalization ( $\mathrm{Vrn}-\mathrm{HI}$ ) in combination with earliness (Eam6) genes. The superiority of the lines carrying the Nure allele at Eam6 was confirmed by factorial ANOVA testing the four possible haplotypes obtained combining alternative alleles at Eam6 and Vrn-H1. Maximum yield potential and differentials among the NT genotypes was finally explored through Finlay-Wilkinson model to interpret grain yield of NT genotypes together with yield adaptability (Ya), as the regression coefficient $b_{\mathrm{i}}$; Ya ranged from 0.71 for NT77 to 1.20 for NT19. Lines simply harboring the Nure variants at the two genes behaved as highest yielding $\left(3.04 \mathrm{t} \mathrm{ha}^{-1}\right)$, and showed the highest yield adaptability $\left(b_{\mathrm{i}}=1.05\right)$. The present study constitutes a starting point towards the introduction of genomic variables in agronomic models for barley grain yield in Mediterranean environments.

\section{Introduction}

Rainfed agricultural areas of the Mediterranean basin are characterized by low and erratic rainfall either in late spring and summer, or throughout the whole crop growth cycle under semi-arid conditions (with annual precipitation 250-500 mm). Since an increased depletion of soil water resources is expected from a gradual rise in temperature, the area is potentially vulnerable to global climate change (Schröter $e t$ al., 2005) and grain yield (GY) of small-grained cereals like durum wheat and barley can be severely influenced. Therefore, minimizing the gap between potential and actual yield, together with increasing GY stability, could be crucial for guaranteeing the cereal crop sustainability (Cattivelli et al., 2008). Barley is predominantly used throughout the Mediterranean region in lower yielding environments, due to its better performance in such input situations compared to durum wheat. The diploid barley is in fact commonly considered less susceptible to the water deprivation periods encountered (Ryan et al., 2008). Its grain 
yield integrates two major components, grain number per unit area (GN) and mean grain weight (GW). Although the two traits are mainly determined at different developmental stages (Miralles and Slafer, 1999), and thus influenced by different conditions and stresses during the growing season, GN and GW are interrelated and subjected to continuous evolutionary trade-off (Sadras, 2007). Nevertheless, as yield components in grain crops are generated throughout the whole crop growing season, yield seems to be much more sensitive to changes in availability of resources in some particular phases than in others. During pre-anthesis, the success of floret set defines the potential grain number (Gonzalez et al., 2003), while grain weight rely on the extent to which post-anthesis conditions favor grain filling (Ugarte et al., 2007). Knowing the critical period when GY is more strongly determined could thus be relevant for developing more adequate strategies for improving yield through either breeding or management. As the rate of physiological development is associated to drought escape, either by avoiding stress during the crop cycle or, more frequently, by avoiding the coincidence of the most sensitive growth phases with the most likely occurrence of the stress, one successful strategy for adaptation in semi-arid environments is a fast rate of development and a short time to flowering and grain maturity (Slafer et al., 2005). It has been proposed this being achieved through fine tuning the proportion of developmental time allocated to the different phenological phases, and allowing the available water to be used by the plant before it is lost from the soil as the temperature increases. The developmental pattern influencing GY and its components relates to the partitioning of a particular crop cycle into different proportions of vegetative and reproductive phases; by allocating different proportions of time to vegetative or reproductive growth, such customization is expected to fit the crop within the variable growing season conferring the ability to maintain its performance under stressful environments (Slafer et al., 2005). A longer time of stem elongation has been associated to an augmented yield potential in wheat and may suggest an alternative avenue for improving $\mathrm{GY}$ (Gonzalez et al., 2003). In barley the different developmental stages (namely vegetative, reproductive, and grain filling phases) show different sensitivity to water deficiency, and the generally faster growth before anthesis compared to wheat might explain its relative success in Mediterranean environments (Tambussi et al., 2005). From a physiological point of view, besides the phenological stage of the plant when the stress conditions act, the primary determinants of GY adaptation to drought in cereals can be expressed as the integrated response of distinct plant processes to limiting resources (Araus et al., 2008). In recent years, several approaches have been used to incorporate explicit information on environmental (ecophysiological) and genetic factors into statistical models for a better understanding of the architecture of the trait as observed across environments (Romagosa et al., 2009). The processes regulating the development of temperate cereals (and ultimately the actual yield) are complex due to interactions between genetic and environmental factors, of which the most important drivers are temperature and photoperiod (Miralles and Slafer, 1999). Genetically, variation at key genomic loci regulating the crop growth cycle can fine tune i) vernalization sensitivity ( $V r n$ genes), ii) photoperiod response (Ppd genes) and iii) early maturity independent from temperature and photoperiod, or earliness per se (Eam or Eps genes).

Despite a large literature accumulated in the past about genotype $x$ environment (GE) interaction for grain yield and its components in crops (van Oosterom et al., 1993; Kang and Gauch, 1996; van Eeuwijk, 2006), empirical studies introducing external environmental, physiological and/or genetic information in the form of co-variables useful to describe G+GE patterns are relatively few (Romagosa et al., 2009). One interesting example has been recently reported for a barley segregating population tested in a wide range of Mediterranean environments and characterized with molecular markers associated to four major regula- tors of pheonological adjustment: $\mathrm{Vrn}-\mathrm{H1}$, $\mathrm{Vrn}-\mathrm{H} 2, \mathrm{Ppd}-\mathrm{H} 2$ and Eam6 (Francia et al., 2011).

Genomics-based approaches provide access to agronomically desirable alleles present at quantitative trait loci (QTLs) and genes affecting crop responses in rainfed environments (Tondelli et al., 2006; Tuberosa and Salvi, 2006; Distelfeld et al., 2009). However, there is a continuous need to integrate disciplines such as genomics, plant physiology and the applied agricultural sciences. Without a strong link with research on plant breeding, agronomy, and crop physiology, the contribution of genomics to crop production under drought stress will remain marginal.

In this study we report a study of barley response to drought using the data generated by the Nure (winter) x Tremois (spring) mapping population, in multi-environment trials across the Mediterranean Basin. In particular, our aims have been: i) to investigate the relationships between a series of agrometeorological variables, GY and its main components (GN and GW), and ii) to interpret adaptation of genotypes with different alleles at major loci of phenological development (Eam6 and $\mathrm{Vrn}-\mathrm{HI}$ ) in terms of genotype main effect and genotype $\mathrm{x}$ environment interaction.

\section{Materials and methods}

\section{Plant material and field trials}

Pure stock seed of the 118 doubled-haploid lines was derived by anther culture from the cross Nure x Tremois, named NTs, and multiplied at ICARDA according to Francia et al. (2004) and (2011), respectively. Nure - [(Fior 40 x Alpha2) x Baraka] - is a winter, two-rowed, Italian feeding variety showing frost tolerance, wide adaptability, high yield potential and yield stability in irrigated as well as in moderately droughted conditions. Tremois - [(Dram x Aramir $)$ x Berac $]$ - is a spring, high yielding, two-rowed, French malting cultivar, adapted to fertile environments. In the frame of Mapping Adaptation of Barley to Droughted Environments (MABDE) project, a multi-environment field trial -18 site-year combinations- was conducted in six countries of the Mediterranean basin (Francia et al., 2011; Table 1) for harvest seasons 2003/2004 and 2004/2005. Locations were contrasting for water holding capacities (AWC, available water holding capacity) of soil and for natural rainfall (high $v s$ low, based on past meteorological data), or for supplemental irrigation when two trials were grown at the same site. Water availability for plants in the field throughout the barley life cycle was characterized by soil water content (SWC) and by a water stress index (WSI), calculated according to Francia et al. (2011). Each site of the multi-environment trial (MET) network was sown in a 15-by-20 rectangular grid of $6 \mathrm{~m}^{2}$ plots. The experimental design consisted of two replicates for the 120 entries (118 NTs plus Nure and Tremois) augmented by four checks repeated 15 times in a systematic diagonal fashion to adjust for spatial variation; the first check, cv. Harmal, was grown at every site, whereas the other three (a landrace, a modern and an old cultivar) varied across sites being relevant to each country in which the trial was being grown.

Phenotypic data were collected in each field trial as already reported by Francia et al. (2011), and in the present work the analyses concentrated on grain yield (GY, $\left.\mathrm{t} \mathrm{ha}^{-1}\right)$, average grain weight (GW, g, calculated as thousand grain weight $10^{-3}$ ), and number of grains per unit area $\left(\mathrm{GN}, \mathrm{m}^{-2}\right.$, calculated as $\left.\mathrm{GY} \mathrm{GW}^{-1}\right)$.

\section{Explicit environmental characterization and data analysis}

A series of environmental co-variables was recorded on a daily basis at each site during the entire length of growing period (LGP, days from 
sowing to harvest). They were minimum and maximum temperature, rainfall, reference evapotranspiration $\left(\mathrm{ET}_{0}\right)$, and solar radiation. Since time to jointing, as well as to physiological maturity were not available for each trial, we followed the indications of Romagosa et al. (2009), and of Francia et al. (2011), after which the period of 3 weeks before heading reasonably includes the largest part of stem elongation, and the most important stages for the determination of grain number in barley, from GS 31 to GS 69. Accordingly, we divided LGP in the four following steps: 1, vegetative growth (days from sowing to heading $-21 \mathrm{~d}$ ); 2 , reproductive growth (days from heading $-21 \mathrm{~d}$ to heading); 3 , early grain filling (days from heading to heading $+14 \mathrm{~d}$ ); 4 , late grain filling (days from days to heading $+14 \mathrm{~d}$ to harvest). To physically characterize the environments during the diverse developmental phases, 14 agrometeorological variables were then calculated/derived: total solar radiation $\left(\mathrm{Sr}, \mathrm{W} \mathrm{m}^{-2}\right)$; number of days with minimum temperature below $0^{\circ} \mathrm{C}(\mathrm{dTb} 0)$; number of days with maximum temperature above $30^{\circ} \mathrm{C}$ (dTa30); average minimum temperature (Tmin); average maximum temperature (Tmax); total growing degree days (GDD); total photothermal quotient ( $\mathrm{PQ}$, calculated as $\left[\mathrm{Sr}\left(\text { mean } \mathrm{T}-4.5^{\circ} \mathrm{C}\right)^{-1}\right]$ ); total evapotranspiration $\left(\mathrm{ET}_{0}, \mathrm{~mm}\right)$; total rainfall $(\mathrm{Rf}, \mathrm{mm})$; total water input (WT, mm, calculated as Rf + irrigation); total water demand (WD, calculated as WT ET ${ }_{0}^{-1} 100$ ); total water consumption (Wcons, calculated as WT+SWC); total water stress index (WSI); WSI to length of growing period (WSI/LGP, WSI d $\mathrm{d}^{-1}$ ). Statistical analysis was conducted using Genstat $11^{\text {th }}$ edition software (Payne et al., 2008) following three main approaches:

i) Relationships between each agrometeorological variables, grain yield, grain number and grain weight were initially investigated by simple correlation calculated on the basis of environmental means of the sites. Multiple linear regressions were then performed to investigate how each set of explanatory variables was associated with the dependent variables GY, GN, and GW. To test for many alternative multiple linear models together, the All-Subset Regression procedure was used, and the best subset of explanatory variables identified according to three different statistics: i) the Adjusted Rsquared accounted for, ii) the Mallows Cp criterion, and iii) the Akaike information criterion. Convergence between the increase in Adjusted $\mathrm{R}^{2}$ and the decrease in Mallows $\mathrm{Cp}$ and AIC values was used to find the best combination from among the starting set of agrometeorological variables.

ii) A mixed model analysis adjusting for row and column effects was applied to generate best linear unbiased estimators (BLUEs) for GY, GN and GW data in each trial. A sites regression (SREG) linearbilinear (multiplicative) model for alternative partitioning of the phenotypic variability was applied to the data in a GGE analysis that models the genotype (G) main effect and genotype $\mathrm{x}$ environment (GE) interaction jointly, by applying a principal components analysis to the genotype by environment two-way table of means - with the genotypes being the objects and the environments being the variables (Yan et al., 2001, 2007). A GGE biplot was constructed by plotting the first principal component (PCA1) scores of the genotypes and the environments against their respective scores for the second principal component (PCA2) that result from singular value decomposition of environment-centered genotype-by-environment data for GY. As an effective visual tool to examine which-won-where in our multi-environment trials, the genotypic classification of the NT lines according to the Eam6-Vrn-H1 haplotype was included in the generated GGE biplot. Further details on the applied model have

Table 1. Trial sites of the Nure $\mathbf{x}$ Tremois population in six countries of the Mediterranean basin for harvest years 2004 and 2005; order follows average grain yields, with fields divided into two subgroups of wet and dry locations.

\begin{tabular}{|c|c|c|c|c|c|c|c|c|c|c|c|c|}
\hline Code & Site & Country & $\begin{array}{c}\text { Location } \\
\text { (Lat - Long) }\end{array}$ & Season & Watering $^{\circ}$ & AWC & $\begin{array}{l}\text { Water } \\
\text { input }\end{array}$ & WSI & PQ 1 & $\begin{array}{c}\text { GY } \\
\left(\mathrm{t} \mathrm{ha}^{-1}\right)\end{array}$ & $\begin{array}{c}\mathrm{GN} \\
\left(\mathrm{m}^{-2}\right)\end{array}$ & $\begin{array}{c}\text { GW } \\
\left(\mathrm{g} 10^{-3}\right.\end{array}$ \\
\hline SYR_5W & Tel Hadya & Syria & $36^{\circ} 01^{\prime} \mathrm{N}-36^{\circ} 56^{\prime} \mathrm{E}$ & $2004 / 2005$ & Wet (rainfed) & 170 & 192 & 39.5 & 940 & 5.43 & 12402 & 43.9 \\
\hline ITA_5W & Foggia & Italy & $41^{\circ} 28^{\prime} \mathrm{N}-15^{\circ} 33^{\prime} \mathrm{E}$ & $2004 / 2005$ & Wet (irrigated) & 130 & 362 & 57.8 & 1328 & 4.88 & 10305 & 47.7 \\
\hline ITA_5F & Fiorenzuola & Italy & $44^{\circ} 55^{\prime} \mathrm{N}-09^{\circ} 54^{\prime} \mathrm{E}$ & $2004 / 2005$ & Wet (rainfed) & 144 & 292 & 31.0 & 912 & 4.58 & - & - \\
\hline TUR_4W & Haymana & Turkey & $39^{\circ} 26^{\prime} \mathrm{N}-32^{\circ} 30^{\prime} \mathrm{E}$ & $2003 / 2004$ & Wet (irrigated) & 150 & 282 & 39.9 & 1237 & 4.44 & 10673 & 41.8 \\
\hline SYR_4W & Tel Hadya & Syria & $36^{\circ} 01^{\prime} \mathrm{N}-36^{\circ} 56^{\prime} \mathrm{E}$ & $2004 / 2005$ & Wet (rainfed) & 170 & 290 & 52.5 & 1106 & 4.13 & 8587 & 48.4 \\
\hline ITA_4W & Foggia & Italy & $41^{\circ} 28^{\prime} \mathrm{N}-15^{\circ} 33^{\prime} \mathrm{E}$ & $2003 / 2004$ & Wet (irrigated) & 130 & 327 & 27.9 & 1096 & 3.78 & 11169 & 34.2 \\
\hline DZA_5W & El Khroub & Algeria & $36^{\circ} 15^{\prime} \mathrm{N}-06^{\circ} 42^{\prime} \mathrm{E}$ & $2004 / 2005$ & Wet (rainfed) & 100 & 130 & 63.6 & 1188 & 3.50 & - & - \\
\hline JOR_5W & Rabba & Jordan & $31^{\circ} 16^{\prime} \mathrm{N}-35^{\circ} 44^{\prime} \mathrm{E}$ & $2004 / 2005$ & Wet (rainfed) & 120 & 217 & 42.8 & 525 & 0.80 & 2334 & 34.7 \\
\hline JOR_4W & Rabba & Jordan & $31^{\circ} 16^{\prime} \mathrm{N}-35^{\circ} 44^{\prime} \mathrm{E}$ & $2003 / 2004$ & Wet (rainfed) & 120 & 194 & 49.5 & 682 & 0.07 & 257 & 16.4 \\
\hline TUR_5 & Haymana & Turkey & $39^{\circ} 26^{\prime} \mathrm{N}-32^{\circ} 30^{\prime} \mathrm{E}$ & $2004 / 2005$ & Dry (rainfed) & 150 & 174 & 27.2 & 1022 & 3.89 & 11434 & 34.0 \\
\hline ITA_5D & Foggia & Italy & $41^{\circ} 28^{\prime} \mathrm{N}-15^{\circ} 33^{\prime} \mathrm{E}$ & $2004 / 2005$ & Dry (rainfed) & 130 & 268 & 63.8 & 1344 & 3.85 & 10139 & 38.2 \\
\hline TUR_4D & Haymana & Turkey & $39^{\circ} 26^{\prime} \mathrm{N}-32^{\circ} 30^{\prime} \mathrm{E}$ & $2003 / 2004$ & Dry (rainfed) & 150 & 232 & 50.5 & 1245 & 3.30 & 7915 & 41.9 \\
\hline ITA_4D & Foggia & Italy & $41^{\circ} 28^{\prime} \mathrm{N}-15^{\circ} 33^{\prime} \mathrm{E}$ & $2003 / 2004$ & Dry (rainfed) & 130 & 258 & 40.4 & 1005 & 3.20 & 10123 & 31.8 \\
\hline SYR_5D & Breda & Syria & $35^{\circ} 56^{\prime} \mathrm{N}-37^{\circ} 10^{\prime} \mathrm{E}$ & $2004 / 2005$ & Dry (rainfed) & 153 & 143 & 63.5 & 1459 & 2.42 & 6394 & 37.2 \\
\hline SYR_4D & Breda & Syria & $35^{\circ} 56^{\prime} \mathrm{N}-37^{\circ} 10^{\prime} \mathrm{E}$ & $2003 / 2004$ & Dry (rainfed) & 153 & 204 & 63.8 & 1011 & 1.35 & 3352 & 40.4 \\
\hline JOR_4D & Ramtha & Jordan & $32^{\circ} 32^{\prime} \mathrm{N}-36^{\circ} 02^{\prime} \mathrm{E}$ & $2003 / 2004$ & Dry (rainfed) & 120 & 151 & 67.2 & 1017 & 1.33 & - & - \\
\hline JOR_5D & Ramtha & Jordan & $32^{\circ} 32^{\prime} \mathrm{N}-36^{\circ} 02^{\prime} \mathrm{E}$ & $2004 / 2005$ & Dry (rainfed) & 120 & 140 & 61.9 & 889 & 0.50 & 1518 & 31.6 \\
\hline ESP_5D & Foradada & Spain & $41^{\circ} 39^{\prime} \mathrm{N}-01^{\circ} 23^{\prime} \mathrm{W}$ & $2003 / 2004$ & Dry (rainfed) & 120 & 167 & 67.7 & 1116 & 0.48 & - & - \\
\hline
\end{tabular}

${ }^{\circ}$ Sites are classified according to previous meteorological data; in some case the wet site was created artificially by supplementary irrigation supplied during the growing season. "Water input, total rainfall plus irrigation (mm) from sowing to harvest. Lat, latitude; Long, longitude; AWC, available water holding capacity $\left(\mathrm{mm} \mathrm{m}^{-1}\right)$ of the soil; WSI, water stress index; PQ 1, total photothermal quotient calculated for the vegetative period as [Solar radiation (mean T -4.5 $\mathrm{C}^{-1}$ ]; GY, average grain yields; GN, grain number for unit area; $\mathrm{GW}$, average grain weight; $\mathrm{N}$, north; E, east; $\mathrm{W}$, west. 
been given elsewhere (Romagosa et al., 2009).

iii)According to the procedures described by Kraakman et al., (2004), Finlay-Wilkinson coefficients $\left(b_{\mathrm{i}}\right)$ were estimated as a measure for yield adaptability (Ya), while Eberhart-Russell mean squared deviations from regressions $\left(s_{\mathrm{i}}^{2}\right)$ were estimated as a measure for yield stability (Ys). Both statistics were based on the regressions of yields for individual genotypes in a trial on an environmental index, here represented by the environment average yield supposed to express the general growing conditions in the trial.

\section{Results}

Phenotypic and agrometeorological data were gathered from 18 trials conducted in six countries of the Mediterranean Basin (Francia et al., 2011). As summarized in Table 1, the NT population showed marked variation in GY across years and locations, ranging from more than $5 \mathrm{t}$ ha $^{-1}$ in the SYR_5W site (Tel Hadya, Syria, in harvest season 2004/2005) to nearly $0 \mathrm{t} \mathrm{ha}^{-1}$ in the JOR_4W site (Rabba, Jordan, in harvest season 2003/2004). Simple correlation analyses, calculated on the basis of environmental means, provided a clear indication of the involvement of specific agrometeorological variables related to the water resource respect to final yield (Table 2). With the only exception of total photothermal quotient $\mathrm{PQ} 1$ (i.e., $\mathrm{PQ}$ calculated from sowing to heading date $-21 \mathrm{~d}$ ), all significant correlations with yield were associated to water-dependent parameters, such as water availability (i.e., $\mathrm{Rf}$ and WT), water consumption (i.e., Wcons and WD) and water stress index either accumulated during the growing season (WSI), or calculated on an average daily basis (WSI/LGP). In total, seven out of 14 environmental co-variables were significantly correlated with GY, whereas ten and four were correlated with GN and GW, respectively. Grain yield and average grain weight showed their highest correlation $\left(r^{2}=0.616\right.$, $\mathrm{P}=0.007$ and $r^{2}=0.703, \mathrm{P}=0.005$, respectively) with water consumption, calculated from sowing to the early grain filling (namely, heading date $+14 \mathrm{~d}$ ); while grain number per unit area showed its highest correlation with the total photothermal quotient calculated for the same period $\left(r^{2}=0.646, \mathrm{P}=0.013\right)$.

Among each set of explanatory variables identified by single correlation, alternative multiple linear models were tested with the All-possible subset selection procedure. Using $\mathrm{GY}$ as response variate, the model maximizing Adj- $\mathrm{R}^{2}$ and, at the same time, minimizing the Mallows $\mathrm{Cp}$ and AIC criteria $(67.01 \%,-0.88$ and 17.12 , respectively), was the one including PQ 1, Wcons 1+2+3, and WSI (Figure 1A). Fitted in an accumulated regression ANOVA, the three terms accounted for $21.9 \%$, $18.3 \%$ and $32.6 \%$ of the total sum of squares, respectively. The same procedure was then applied to $\mathrm{GN}$, and the subset of selected variates included Sr 1+2+3, PQ 3, WD 1 and WSI/LGP (Figure 1B), accounting for $31.4 \%, 10.8 \%, 3.5 \%$ and $47.2 \%$ of the total sum of squares, respectively. Finally, only Wcons $1+2+3$ was retained as determinant of GW (Figure 1C) and it explained $49.5 \%$ of the total sum of squares.

After survey of influence of meteo variables on GY, the effect on GY of important loci that are known to regulate barley growth and development has been verified. The mechanistic importance of few simple growth cycle determinants on barley grain yield was already demonstrated in the NT dataset by introducing molecular marker information that classify allelic variation at four phenological genomic loci: $\mathrm{Vrn}-\mathrm{H1}$, Vrn-H2, Ppd-H2 and Eam6 (Francia et al., 2011). This approach revealed being suitable in understanding both the genotype main effect and the genotype $\mathrm{x}$ environment variability. To better interpret adaptation of genotypes, we aimed at visualizing patterns in yield-trial data with principal components $\mathrm{G}+\mathrm{GE}$ (departure from location means), and

Table 2. Correlations of agrometeorological variables with grain yield, grain number for unit area, and average grain weight. Only significant values $(P \leq 0.05)$ are reported.

\begin{tabular}{|c|c|c|c|c|c|c|c|c|}
\hline MeteoVar ${ }^{\circ}$ & $\begin{array}{l}\text { GY } \\
r^{2}\end{array}$ & P value & MeteoVar & $\begin{array}{c}\text { GN } \\
r^{2}\end{array}$ & P value & MeteoVar & $\begin{array}{c}\text { GW } \\
r^{2}\end{array}$ & P value \\
\hline PQ 1 & 0.468 & 0.050 & Sr $1+2+3$ & 0.560 & 0.037 & Sr $1+2$ & 0.564 & 0.036 \\
\hline Rf 2 & 0.556 & 0.017 & Tmin $1+2+3$ & -0.627 & 0.016 & $\mathrm{Sr}$ & 0.617 & 0.019 \\
\hline $\mathrm{Rf}$ & 0.526 & 0.025 & $\operatorname{Tmax} 1+2+3$ & -0.634 & 0.015 & PQ 1 & 0.545 & 0.044 \\
\hline WT 2 & 0.556 & 0.017 & PQ 1 & 0.562 & 0.036 & $\mathrm{PQ} 1+2$ & 0.580 & 0.030 \\
\hline WT $1+2+3$ & 0.504 & 0.033 & $P Q 1+2+3$ & 0.646 & 0.013 & Wcons 1 & 0.665 & 0.009 \\
\hline WT & 0.572 & 0.013 & Rf 2 & 0.592 & 0.026 & Wcons $1+2$ & 0.700 & 0.005 \\
\hline Wcons 2 & 0.475 & 0.046 & WT 2 & 0.592 & 0.026 & Wcons $1+2+3$ & 0.703 & 0.005 \\
\hline Wcons 1+2 & 0.563 & 0.015 & $\mathrm{ET}_{0} 1$ & 0.612 & 0.020 & Wcons & 0.687 & 0.007 \\
\hline Wcons $1+2+3$ & 0.616 & 0.007 & WD 1 & -0.582 & 0.029 & $\mathrm{ET}_{0}$ & 0.577 & 0.031 \\
\hline Wcons & 0.612 & 0.007 & WSI 4 & -0.636 & 0.015 & - & - & - \\
\hline WD 2 & 0.478 & 0.047 & WSI/LGP & -0.636 & 0.015 & - & - & - \\
\hline WSI - & 0.469 & 0.050 & - & - & - & - & - & - \\
\hline WSI/LGP & -0.528 & 0.024 & - & - & - & - & - & - \\
\hline
\end{tabular}

${ }^{\circ}$ Each variable was calculated either for the LGP (days from sowing to harvest) or for its components. LGP, length of growing period; GY, grain yield; GN, grain number for unit area; GW, average grain weight; MeteoVar, meteorological variables; PQ 1, total photothermal quotient calculated for 1; Sr 1+2+3, total solar radiation ( $\mathrm{W} \mathrm{m}^{-2}$ ) for 1, 2, and 3; 1, vegetative growth (days from sowing to heading -21 d); 2, reproductive growth (days from heading -21 d to heading); 3 , early grain filling (days from heading to heading $+14 \mathrm{~d}$ ); Sr 1+2, total solar radiation $\left(\mathrm{W} \mathrm{m}^{-2}\right.$ ) for 1 and 2; Rf 2, total rainfall (mm) for 2; Tmin $1+2+3$, average minimum temperature for 1,2 , and 3 ; Sr, total solar radiation $\left(\mathrm{W} \mathrm{m}^{-2}\right.$ ); Rf, total rainfall $(\mathrm{mm})$; Tmax 1+2+3, average maximum temperature for 1,2 , and 3 ; WT 2, water input as total rainfall + total irrigation (mm) for 2; PQ 1+2, total photothermal quotient calculated for 1 and 2; WT 1+2+3, water input as total rainfall + total irrigation (mm) for 1,2, and 3; PQ 1+2+3, total photothermal quotient calculated for 1,2, and 3; Wcons 1, water consumption (WT + SWC) for 1; WT, water input as total rainfall + total irrigation (mm); Rf 2, total rainfall (mm) for 2; Wcons 1+2, water consumption (WT + SWC) for 1 and 2; Wcons 2, water consumption (WT + SWC) for 2; WT 2, water input as total rainfall + total irrigation (mm) for 2 ; Wcons $1+2+3$, water consumption (WT + SWC) for 1, 2, and 3; ET 1 , total evapotranspiration (mm) for 1 ; Wcons, water consumption (WT + SWC); WD 1 , water input to $\mathrm{ET}_{0}$ (WT ET ${ }_{0}^{-1} 100$ ) for 1 ; $\mathrm{ET}_{0}$, total evapotranspiration (mm); WSI 4, water stress index for 4; 4, late grain filling (from days to heading $+14 \mathrm{~d}$ to harvest); WD 2 , water input to $\mathrm{ET}_{0}$ (WT ET -1 100) for 2 ; WSI, water stress index; WSI/LGP, WSI to length of growing period (WSI d ${ }^{-1}$ ). 
A.

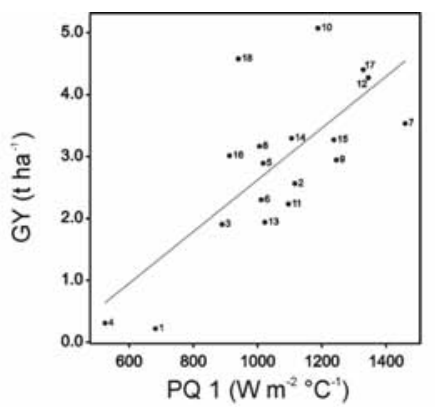

B.

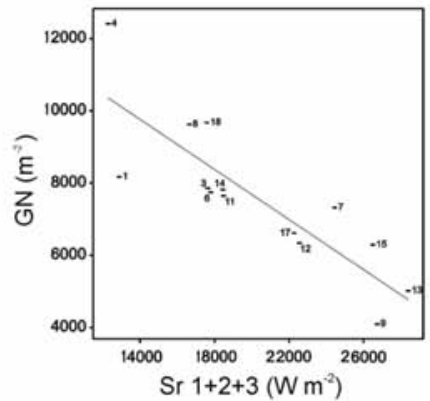

C.

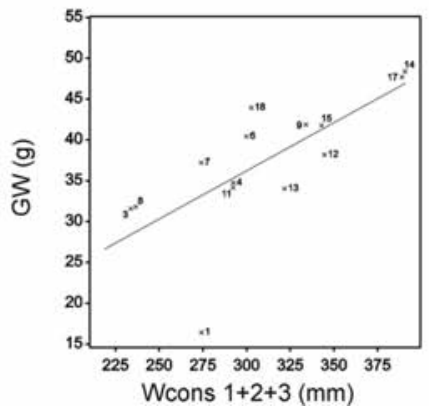

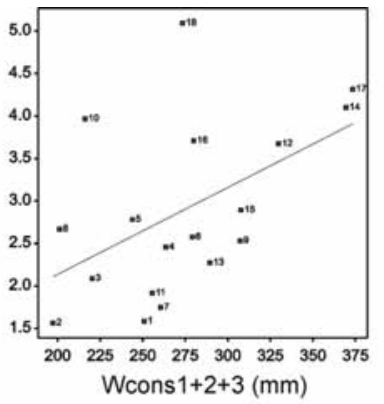

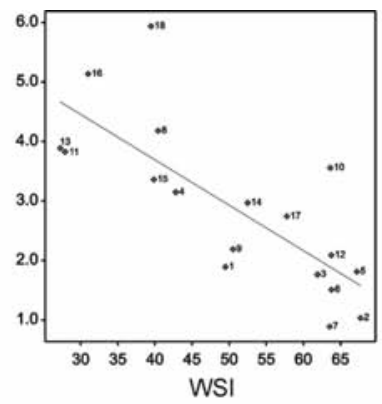

Low-Yield Env High-Yield Env

1: JOR_4W 8: ITA 4D

2: ESP $^{-} 5 \mathrm{D}$ 9: TUR $4 \mathrm{D}$

3: JOR-5D 10: DZA 5W

4: JOR_5W 11: ITA_4W

5: JOR_4D 12: ITA_5D

6: SYR 4D 13: TUR 5

7: SYR-5D 14: SYR 4W

15: TUR 4W

16: ITA $\overline{5} \mathrm{~F}$

17: ITA $5 \mathrm{~W}$

18: SYR_5W
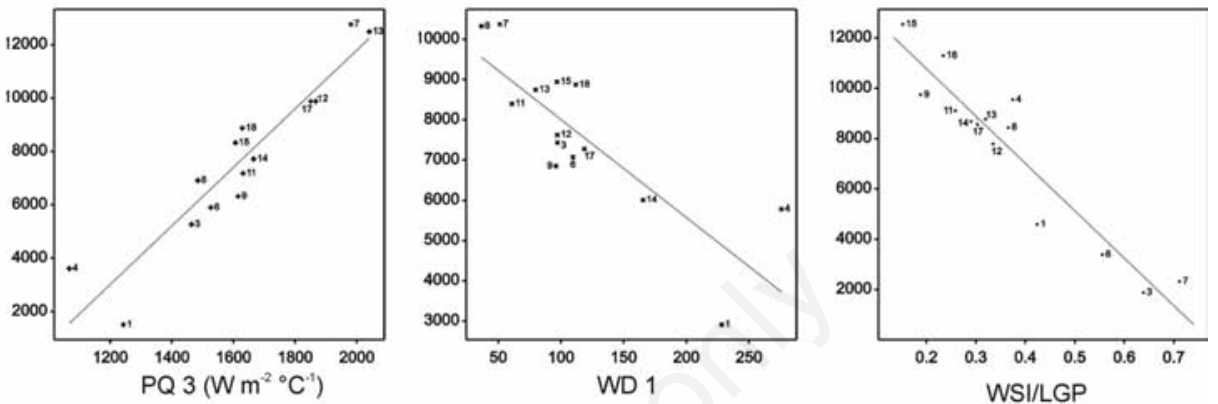

Figure 1. Fitted relationships of the linear regression models between grain yield (A), grain number per unit area (B) and average grain weight $(C)$ with the selected meteorological explanatory variables in the multi-environment trial of the Nure $\mathbf{x}$ Tremois population.

thereby showing which genotype won where. The GGE biplot for the NT population in our multi-environment trial (Figure 2) indicates in fact the best performing genotypes in each environment and group of environments. As position of genotypes is given by the estimates for their genotypic scores and the coordinates for the environments originate from the estimates for the environmental scores, distances from the origin are proportional to the amount of interaction due to genotypes over environments or to environments in relation to genotypes. In this study, PCA1 and PCA2 accounted for 26.86 and $20.82 \%$ of the total $\mathrm{G}+\mathrm{GE}$, respectively, and a total of $47.67 \%$ of $\mathrm{G}+\mathrm{GE}$ sum of squares. As expected, more differences are visible in site means than in genotypic means. On one hand, NT lines carrying the Nure allele at Vrn-H1 (with the scores of genotypes furthest from the origin along first axis) indicate their association with TUR_4W and TUR_4D scores, showing that they were most responsive to these environments. On the other hand, genotypes carrying the Nure early allele at Eam6 in combination to the Tremois vernalization insensitive allele at $\mathrm{Vrn}-\mathrm{HI}$ had clear association with the conditions that were met in DZA_5W (planted in early spring; Table 1). We can conclude that PCA1 is apparently driven by cold temperatures pointing to autumn-sown TUR_4W and TUR_4D trials, whereas second axis mainly showed the differential behavior of DZA_5W and, to a lesser extent, of SYR_5D, respect to the rest of environments. The conditions observed at TUR_4D could be considered an ideal environment for exploiting maximum yield potential and differentials among the NT genotypes. In fact, according to Yan et al. (2001), the best selection environments are those with small (absolute) PCA2 score (more representative of the overall environment), and large PCAl score (more power to

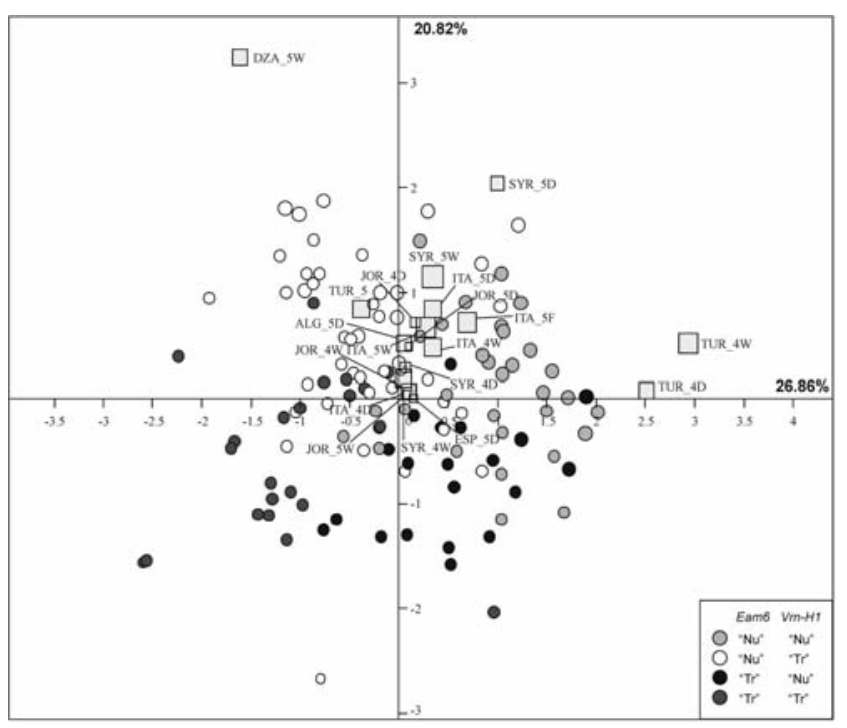

Figure 2. GGE biplot on the 120 Nure $\mathrm{x}$ Tremois genotypes within the 18 Mediterranean environments. The scatter plot, based on environment-centered data and scaled for genotype eigen values, derives from the genotype by environment table. Squared and circled symbols are drawn proportionally to mean site yield and average genotypic yield across sites, respectively. Genotypes are color-coded according to their Eam6-Vrn-H1 haplotype as reported in legend. 
discriminate genotypes in terms of the genotype main effect). FinlayWilkinson model applied with the R joint procedure allowed to interpret grain yield of NT genotypes together with yield adaptability represented by the regression coefficient $b_{\text {i. }}$. As shown in the resulting scatter plot, GY of genotypes averaged over all locations ranged from $2.04 \mathrm{t} \mathrm{ha}^{-1}$ for NT77 to $3.83 \mathrm{t} \mathrm{ha}^{-1}$ for NT101; the overall mean was $2.89 \mathrm{t} \mathrm{ha}^{-1}$ (Figure 3). Yield adaptability (Ya) ranged in NT lines from 0.71 again for NT77 to 1.20 for NT19; the average being 0.99 . Figure 3 shows the apparent superiority of those genotypes carrying the Nure allele at Eam6 (indicated by black circles), and this was confirmed testing by factorial ANOVA the four possible haplotypes (i.e., couples of allelic combinations) obtained combining alternative alleles at Eam6 and Vrn-H1 (Table 3). In our multi-environment trial, genotypes harboring the $\mathrm{Nu}-\mathrm{Nu}$ haplotype at the two loci regulating the cycle behaved with the highest grain yield $\left(3.04 \mathrm{t} \mathrm{ha}^{-1}\right)$ coupled with the highest yield adaptability $\left(b_{\mathrm{i}}=1.05\right)$. No significant differences were instead found in the level of yield stability (Ys) among the four haplotype groups.

\section{Discussion}

Climatic factors like temperature, solar radiation and water availability affect crop yield all over the world (Araus et al., 2003, 2008; Bingham et al., 2007). As an example, 0.6 to $8.9 \%$ reduction in wheat yield per $1^{\circ} \mathrm{C}$ rise in temperature has been reported by Lobell and Field (2007). Global climate change is also expected to make the situation worse in the near future. Therefore, it is important to understand the influence of the meteorological variables on GY and its components during the different phases of crop development, especially in fragile environments as the Mediterranean ones.

Solar radiation ( $\mathrm{Sr}$ ) might be an important environmental factor which brings positive changes in the crop growth by altering leaf architecture and light partitioning. Similarly, solar radiation activates the photosystem by which light reaction of photosynthesis started, and electrons generated by photolysis of water moves to produce energy carriers (e.g., NADPH and ATP). The results showed here highlight that with the increase in solar radiation from sowing to early grain filling, GN decreased significantly. Multiple regression analysis linked this variation to a decrease in GN, as water demand in the vegetative phase (WD 1) increased, together with average water stress index during the entire crop cycle (WSI/LGP) (Figure 1B).

Photothermal quotient (PQ) portrayed the combined effect of solar radiation and temperature on crop yield. It is considered a determinant factor that affect cereal yield significantly, mainly through the GN component (Estrada-Campuzano et al., 2008; Sandaña and Pinochet, 2011). Our results clearly indicated a strong relationship of photothermal quotient measured during both the vegetative growth (from sowing to heading $-21 \mathrm{~d}$ ) and early grain filling (from heading to heading $+14 \mathrm{~d}$ ) with grain yield and grain number determination (Figure 1A,B). Although with a lower precision in the division of the crop growth cycle, similar results have been obtained in bread wheat (Ahmed et al., 2011), suggesting once again that the two crops share common mechanisms of GY determination, and notably, that results obtained in barley may apply also to wheat.

Barley genomic regions significantly associated with grain yield in 28 Mediterranean environments have been identified using a germplasm collection of genotypes that represented landraces, old, and contemporary cultivars (Comadran et al., 2008). More recently, Francia et al. (2011) investigated in the same geographic range presented here the influence of the length of the different phenological phases in determining barley adaptation, and found that GY was in general more limited by GN than by GW. As stated by Savin and Slafer (1991), this can be viewed as a consequence of the crucial role played by the timing of occurrence of flowering in defining the broad adaptation of a given genotype and thus for grain yield determination. Crop ontogeny tends to be tailored to the target environment to avoid adverse conditions during the most critical stages (Slafer et al., 2009). The period before the start of the grain-filling is very important for the determination of grain number and despite some uncertainty about the actual beginning and the end of this critical period, it is generally accepted that it covers the period from late stem elongation to early post-flowering in wheat (Fischer, 1985; Savin and Slafer, 1991) and from early stem elongation to anthesis in barley (Bingham et al., 2007). The results presented here indicate a possible involvement of the early post-flowering period in determining GN, together with the pre-anthesis period, and thus appear to be in greater agreement with what was found in wheat rather than in barley (Table 2; Figure 1). However, additional studies will be necessary to definitively clarify this issue. In all cases this entails that, as the flowering date occurs later in the season, an increased risk of (terminal) drought arises during grain filling. Therefore, extending duration of the stem elongation phase at the expense of shortening the vegetative phase has been proposed as a promising breeding tool in small grains (Borras et al., 2009; Francia et al., 2011).

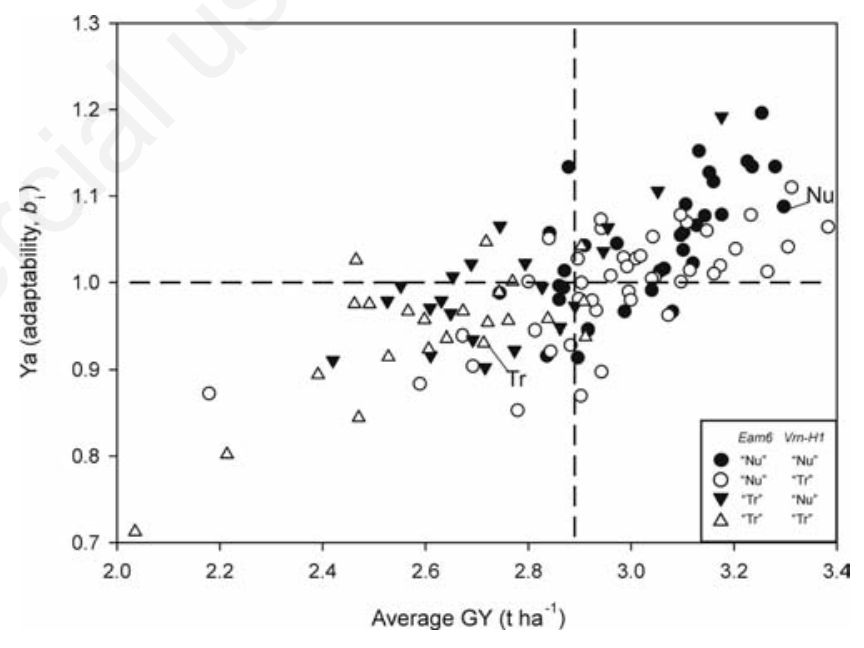

Figure 3. Scatter plot between yield adaptability (Ya) and average grain yield (GY) (environmental index) of Nure $\mathrm{x}$ Tremois genotypes. Horizontal and vertical dashed lines represent mean coefficient regression and mean yield across the multi-environment trial, respectively. Genotypes symbols are color-coded according to their Eam6-Vrn-H1 haplotype as reported in legend.

Table 3. Least-square means of haplotype classes at major developmental loci Eam6-Vrn-H1 for grain yield, yield adaptability, and yield stability.

\begin{tabular}{lccc} 
Haplotype class & GY $\left(\mathrm{t} \mathrm{ha}^{-1}\right)$ & Ya $\left(b_{i}\right)$ & Ys $\left(s^{2} \mathrm{i}\right)$ \\
$\mathrm{Nu}-\mathrm{Nu}$ & $3.04^{\mathrm{a}}$ & $1.05^{\mathrm{a}}$ & $0.52^{\mathrm{a}}$ \\
$\mathrm{Nu}-\mathrm{Tr}$ & $2.98^{\mathrm{a}}$ & $1.00^{\mathrm{b}}$ & $0.51^{\mathrm{a}}$ \\
\hline $\mathrm{Tr}-\mathrm{Nu}$ & $2.75^{\mathrm{b}}$ & $1.00^{\mathrm{b}}$ & $0.46^{\mathrm{a}}$ \\
$\operatorname{Tr}-\mathrm{Tr}$ & $2.61^{\mathrm{b}}$ & $0.94^{\mathrm{c}}$ & $0.48^{\mathrm{a}}$ \\
\hline
\end{tabular}

${ }^{\circ}$ Multiple comparison are based on Tukey's Honestly-Significant-Difference test $(\mathrm{P} \leq 0.05)$. GY, grain yield; Ya, yield adaptability; Ys, yield stability; Nu-Nu, Nure-Nure; Nu-Tr, Nure-Tremois; Tr-Nu, TremoisNure; Tr-Tr, Tremois-Tremois. ${ }^{a, b}$ Within column, numbers followed by the same letter are not significantly different at $\mathrm{P} \leq 0.05$ 
Site regression model (Cornelius et al., 1996) with first two principal components has been widely used to generate GGE biplots that provide great insights into relationships of both the genotype and genotype $\times$ environment interaction main effects (Yan et al., 2001). Results obtained in our experiment demonstrate a clear pattern of adaptation for NT genotypes across Mediterranean environments explained by just two genomic loci (Figure 2). On one hand, superiority of Eam6 allele from Nure across environments is suggested by the GGE biplot as open and light gray circles seem to have bigger diameter (i.e., larger average yields across sites) than Eam6 allele from Tremois. On the other hand, genotypes with specific adaptation are driven by mainly $\mathrm{Vrn}-\mathrm{H} 1$ as they appear best adapted to cold environments (both Turkish sites for harvest year 2004); much worst for NT genotypes harboring the vernalization insensitive $\mathrm{Vrn}$-H1 allele from Tremois.

After having explored G+GE main effects with different alleles at the two major loci of phenological development (Eam6 and Vrn-H1), we tried to interpret yield adaptability and stability measured as regression coefficient and mean squared deviations from regressions (FinlayWilkinson $b_{\mathrm{i}}$ and Eberhart-Russell $s_{\mathrm{i}}{ }^{2}$, respectively). The range of Finlay-Wilkinson slopes for the relationship between the environmental index and observed yield that we obtained for the NT genotypes (0.71-1.20) agrees with that reported by Kraakman et al. (2004) for 146 modern European two-rowed spring barley cultivars. Genotypes with low $b_{\mathrm{i}}$ values (low adaptability) and high mean square values (low yield stability) are genotypes that yield more under drought conditions, but are not able to respond to higher levels of moisture.

In general, our results confirm the hypothesis that genotypes selected (adapted) under high yielding environments like Nure perform better than those with lower yield potential when grown in a wide range of Mediterranean environments. Otherwise stated, selection for high yield in stress-free conditions gets, to a certain extent, indirectly improved yield also in many water-limiting conditions (Araus et al., 2008; Cattivelli et al., 2008). Retrospective studies on wheat indicate that the improvement in yield has more often been associated with augmented partitioning of biomass to the grain than with enhanced overall biomass (Slafer et al., 2009). However, it is becoming more important than ever to unravel the genetic and physiological bases of above ground biomass conversion from light and biomass determination if increased yields are to be achieved (Araus et al., 2008). As -omics sciences (e.g., genomics and proteomics) boosted during the past few decades, they are expected to enable systematic analysis of changes that occur in plants in response to environmental conditions (Pecchioni et al., 2012). However, crop scientists must remember that, as happened during the green revolution, the contribution of molecular biology cannot be separated from that of agricultural sciences.

The present characterization of barley genotypes for yield adaptability, as well as GE interaction, constitutes a starting point towards the improvement of barley yield in future Mediterranean agriculture.

\section{References}

Ahmed M, Hassan FU, Aslam MA, Akram MN, Akmal M, 2011. Regression model for the study of sole and cumulative effect of temperature and solar radiation on wheat yield. Afr. J. Biotechnol. 10:9114-21.

Araus JL, Slafer G., Royo C, Serret M, 2008. Breeding for yield potential and stress adaptation in cereals. Critical Rev. Plant Sci. 27:377-412.

Araus JL, Villegas D, Aparicio N, Garcia del Moral LF, El Hani S, Rharrabti Y, Ferrio JP, Royo C, 2003. Environmental factors determining carbon isotope discrimination and yield in durum wheat under Mediterranean conditions. Crop Sci. 43:170-80.
Bingham IJ, Blake J, Foulkes MJ, Spink J, 2007. Is barley yield in the UK sink limited? I. Post-anthesis radiation interception, radiation use efficiency and source-sink balance. Field Crop Res. 101:198211.

Borras G, Romagosa I, van Eeuwijk F, Slafer GA, 2009. Genetic variability in duration of pre-heading phases and relationships with leaf appearance and tillering dynamics in a barley population. Field Crop Res. 113:95-104.

Cattivelli L, Rizza F, Badeck F-W, Mazzucotelli E, Mastrangelo AM, Francia E, Marè C, Tondelli A, Stanca AM, 2008. Drought tolerance improvement in crop plants: An integrated view from breeding to genomics. Field Crop Res. 105:1-14.

Comadran J, Russell J, van Eeuwijk F, Ceccarelli S, Grando S, Baum M, Stanca A, Pecchioni N, Mastrangelo A, Akar T, Al-Yassin A, Benbelkacem A, Choumane W, Ouabbou H, Dahan R, Bort J, Araus J-L, Pswarayi A, Romagosa I, Hackett C, Thomas WTB, 2008. Mapping adaptation of barley to droughted environments. Euphytica. 161:35-45.

Cornelius PL, Crossa J, Seyedsadr MS, 1996. Statistical tests and estimators for multiplicative models for cultivar trials. In: M.S. Kang et al. (eds.) Genotype-by-environment interaction. CRC Press, Boca Raton, FL, pp 199-234.

Distelfeld A, Li C, Dubcovsky J, 2009. Regulation of flowering in temperate cereals. Curr. Op. Plant Biol. 12:178-84.

Estrada-Campuzano G, Miralles DJ, Slafer GA, 2008. Yield determination in triticale as affected by radiation in different development phases. Eur. J. Agron. 28:597-605.

Fischer RA, 1985. Number of kernels in wheat crops and the influence of solar radiation and temperature. J. Agric. Sci. 105:447-61.

Francia E, Rizza F, Cattivelli L, Stanca AM, Galiba G, Toth B, Hayes PM, Skinner JS, Pecchioni N, 2004. Two loci on chromosome 5H determine low temperature tolerance in a 'Nure' (winter) x 'Tremois' (spring) barley map. Theor. Appl. Genet. 108:670-80.

Francia E, Tondelli A, Rizza F, Badeck FW, Li Destri Nicosia 0, Akar T, Grando S, Al-Yassin A, Benbelkacem A, Thomas WTB, van Eeuwijk F, Romagosa I, Stanca AM, Pecchioni N, 2011. Determinants of barley grain yield in a wide range of Mediterranean environments. Field Crop Res. 120:169-78.

Gonzalez FG, Slafer GA, Miralles DJ, 2003. Grain and floret number in response to photoperiod during stem elongation in fully and slightly vernalized wheats. Field Crop Res. 81:17-27.

Kang MS, Gauch HG, 1996. Genotype-by-environment interaction. CRC Press, Boca Raton, FL, USA.

Kraakman ATW, Niks RE, Van Den Berg PMMM, Stam P, Van Eeuwijk FA, 2004. Linkage disequilibrium mapping of yield and yield stability in modern spring barley cultivars. Genetics. 168:435-46.

Lobell DB, Field CB, 2007. Global scale climate-crop yield relationships and the impacts of recent warming. Env. Res. Lett. 2: 014002.

Miralles DJ, Slafer GA, 1999. Wheat development. In: E.H. Satorre and G.A. Slafer (eds.) Wheat: Ecology and physiology of yield determination. Food Product Press, New York, pp 13-43.

Payne RW, Harding SA, Murray DA, Soutar DM, Baird DB, Welham SJ, Kane AF, Gilmour AR, Thompson R, Webster R, Tunnicliffe Wilson G, 2008. GenStat Release 11 Reference Manual, Part 2 Directives. VSN International, Hemel Hempstead, Hertfordshire, UK.

Pecchioni N, Milc JA, Pasquariello M, Francia E, 2012. Barley: Omics approaches for abiotic stress tolerance. In: N. Tuteja, S. Singh Gill, A.F. Tiburcio, R. Tuteja (eds.) Improving Crop Resistance to Abiotic Stress. Wiley-VCH, Weinheim, pp 777-882.

Romagosa I, van Eeuwijk FA, Thomas WTB, 2009. Statistical analyses of genotype by environment data. In: M.J. Carena (ed.) Cereals. Handbook of plant breeding series. Spinger, New York, vol. 3, pp 1-41. Ryan J, Singh M, Pala M, 2008. Long-term cereal-based rotation trials 
in the Mediterranean region: implications for cropping sustainability. Adv. Agron. 97:273-319.

Sadras V0, 2007. Evolutionary aspects of the trade-off between seed size and number in crops. Field Crop Res. 100:125-38.

Sandaña P, Pinochet D, 2011. Ecophysiological determinants of biomass and grain yield of wheat under P deficiency. Field Crop Res. 120:311-9.

Savin R, Slafer GA, 1991. Shading effects on the yield of an Argentinian wheat cultivar. J. Agric. Sci. 116:1-7.

Schröter D, Cramer W, Leemans R, Prentice IC, Araújo MB, Arnell NW, Bondeau A, Bugmann H, Carter TR, Gracia CA, de la Vega-Leinert AC, Erhard M, Ewert F, Glendining M, House JI, Kankaanpää S, Klein RJT, Lavorel S, Lindner M, Metzger MJ, Meyer J, Mitchell TD, Reginster I, Rounsevell M, Sabaté S, Sitch S, Smith B, Smith J, Smith P, Sykes MT, Thonicke K, Thuiller W, Tuck G, Zaehle S, Zierl B, 2005. Ecosystem service supply and vulnerability to global change in Europe. Science 310:1333-7.

Slafer GA, Araus JL, Royo C, Garcia del Moral LF, 2005. Promising ecophysiological traits for genetic improvement of cereal yields in Mediterranean environments. Ann. Appl. Biol. 146:61-70.

Slafer GA, Kantolic AG, Appendino ML, Miralles DJ, Savin R, 2009. Crop development: genetic control, environmental modulation and relevance for genetic improvement of crop yield. In: V.0. Sadras, D.F. Calderini (eds.) Crop physiology. Application for genetic improvement and agronomy. Academic Press/Elsevier, Oxford, UK, pp 277-308.
Tambussi EA, Nogues S, Ferrio P, Voltas J, Araus JL, 2005. Does higher yield potential improve barley performance in Mediterranean conditions? A case study. Field Crop Res. 91:149-60.

Tondelli A, Francia E, Barabaschi D, Aprile A, Skinner JS, Stockinger EJ, Stanca AM, Pecchioni N, 2006. Mapping regulatory genes as candidates for cold and drought stress tolerance in barley. Theor. Appl. Genet. 112:445-54.

Tuberosa R, Salvi S, 2006. Genomics-based approaches to improve drought tolerance of crops. Trends Plant Sci. 11:405-12.

Ugarte C, Calderini DF, Slafer GA, 2007. Grain weight and grain number responsiveness to pre-anthesis temperature in wheat, barley and triticale. Field Crop Res. 100:240-8.

van Eeuwijk, F, 2006. Genotype by environment interaction - Basics and beyond. In: K.R. Lamkey and M. Lee (eds.) Plant breeding: The Arnel R. Hallauer International Symposium. Blackwell publishing, pp 155-170.

van Oosterom J, Kleijn D, Ceccarelli S, Nachit MM, 1993. Genotype-byenvironment interactions of barley in the Mediterranean region. Crop Sci. 33:669-74.

Yan W, Cornelius PL, Crossa J, Hunt LA, 2001. Two types of GGE biplots for analyzing multi-environment trial data. Crop Sci. 41:656-63.

Yan W, Kang MS, Baoluo Ma B, Woods S, Cornelius PL, 2007. GGE biplot vs. AMMI analysis of genotype-by-environment data. Crop Sci. 47:643-53. 